\title{
Enhancing Student Learning by Providing a Failure Risk-free Environment and Experiential Learning Opportunities
}

\section{Stephen J. Phillips, University of Waterloo}

Graduate student studying civil engineering at the University of Waterloo.

\section{Kayleanna Giesinger, University of Waterloo}

Kayleanna is a third year Undergraduate student in Environmental Engineering student at the University of Waterloo. She has been involved in extensive engineering education research with Professor Rania Al-Hammoud through applying to grants and helping with events. She is very passionate about the future of education.

\section{Dr. Rania Al-Hammoud P.Eng., University of Waterloo}

Dr. Al-Hammoud is a Faculty lecturer (Graduate Attributes) in the department of civil and environmental engineering at the University of Waterloo. Dr. Al-Hammoud has a passion for teaching where she continuously seeks new technologies to involve students in their learning process. She is actively involved in the Ideas Clinic, a major experiential learning initiative at the University of Waterloo. She is also responsible for developing a process and assessing graduate attributes at the department to target areas for improvement in the curriculum. This resulted in several publications in this educational research areas. Dr. Al-Hammoud won the "Ameet and Meena Chakma award for exceptional teaching by a student" in 2014 and the "Engineering Society Teaching Award" in 2016 from University of Waterloo. Her students regard her as an innovative teacher who continuously introduces new ideas to the classroom that increases their engagement.

\section{Prof. Scott Walbridge}

Scott Walbridge has been a structural engineering professor in the University of Waterloo's Department of Civil and Environmental Engineering since 2006. Prior to that, he completed his doctoral studies at the Ecole Polytechnique Federale de Lausanne (EPFL), and his bachelor's and master's degrees at the University of Alberta. Between his master's and doctoral studies, he worked as a structural engineering consultant for 2.5 years in Edmonton, Canada.

\section{Dr. Chris Carroll, Saint Louis University}

Dr. Carroll is an Assistant Professor in the Department of Civil Engineering at Saint Louis University. His experimental research interests focus on reinforced and prestressed concrete, while his engineering education research interests focus on experiential learning at both the university and K-12 levels. Dr. Carroll serves as a voting member on ACI Committee S802 - Teaching Methods and Educational Materials and is Chair of the Career Guidance Committee for the ASCE - St. Louis Section. He has eight years of formal experience with K-12 engineering education. 


\title{
Enhancing Student Learning by Providing a Failure Risk Free Environment and Experiential Learning Opportunities
}

\begin{abstract}
In second year civil engineering, students participate in a horizontally integrated bridge design project to increase their exposure to engineering application and prepare for their fourthyear design project. To compliment this project, a two-day event called CivE Days was implemented. This event freed students from classes and deadlines and allowed them to completely immerse themselves in a simulated bridge design project. The set-up of the event is split into four stages: preliminary design, bridge construction, bridge testing and project reflection. Learning takes place through a combination of experiential learning, group work, reflective learning, and learning from failure. All of these pedagogical approaches promote a deeper level of learning for students and enhance knowledge retention in upper years. The event was not graded to allow students to experiment and learn in a stressfree environment. This provided a positive atmosphere where design creativity was encouraged without fear of failure. The effectiveness of the CivE Days initiative was evaluated through the final bridge project testing results, final bridge project report marks, and surveys submitted at the end of the CivE Days event. The bridge project grades and testing results for students who participated in CivE Days was compared to the bridge project grades and testing results for a control class who did not have the opportunity to participate in the CivE Days event. It was found that student grades and performance improved, indicating a better understanding of the bridge design project and how the information from the different courses are integrated.
\end{abstract}

\section{Introduction}

Diversification of teaching methods is vital for an inclusive and deeper learning environment. Instructors are constantly working towards improving student learning and steps have already been taken to do this in the civil engineering curriculum. Two years ago, changes were made to incorporate a horizontally integrated bridge design project in the second-year civil program. This bridge project requires students to design, build, and test a bridge, using concepts from their core courses (Structure and properties of materials, probability and statistics, solid Mechanics and transportation principals. The details of this bridge design project (popsicle sticks bridge) are explained by Balkos et al. in (Balkos, 2017). Since then, the following areas of concern have been brought up:

- Students have admitted to doing the work last minute due to the demanding nature of all their courses.

- There have been complaints of students being too nervous to try different methods because of a lack of understanding, time, and experience.

- Students only have time to make one bridge, and they do not test the bridge design beforehand. When testing, bridge designs fail in ways other than what was predicted.

CivE Days was developed as a two-day event with hands-on activities to address each of these issues along with improving learning techniques. 
The intended outcomes of this event aimed at allowing students to have a better understanding of the popsicle sticks bridge design project requirements and how the information from the different courses are integrated as explained in Balkos et al., 2017. Through CivE Days, students have the supervised time that allows them to increase their exposure and experiment with the required design components of the project. This gives students early exposure to project concepts which prevents them from starting their project last minute. As a result, it was predicted that the final bridge design projects would be completed with better quality, more creative designs, and demonstrate a better understanding of related concepts from their courses.

The learning methods utilized in CivE Days include student interest directed learning, experiential learning, learning through failure, and reflective learning. The handson nature of CivE Days and the layout of the tasks within it allows for diverse learning techniques and thorough reflections. The event was not graded to allow students to experiment and learn in a stress-free atmosphere. The testing and reflection aspects of CivE Days allows students to learn through failure. All of these pedagogical approaches promote a deeper level of learning for students and enhance retention in upper years.

\section{Literature Review}

Each learning technique incorporated into CivE Days is uniquely vital to the overall success and improvement of the bridge project. In a paper by Lynch et al. (2012), the importance of exposure to material ahead of a final project is emphasized. They state that after doing experimentation, many students modified their designs for the final project. The time and preparation ahead of the project gave students the opportunity to have a stronger knowledge base for their material which enabled them to modify and improve their work. Whitman et al. (2017) support this further by stating, "while any assessment requires some types of active retrieval, having students reconstruct what they know through alternative assessments leads to deeper understanding and consolidates learning in more powerful ways than traditional". CivE Days served to reconstruct students' knowledge foundation for the final bridge project. This foundation is solidified further through student interest directed learning, experiential learning, learning through failure, and reflective learning.

The need for experiential learning is what initiated the incorporation of the bridge project. The benefits of experiential learning is stated clearly by Current and Kowalske (2016), as "encouraging students to generate an extensive and flexible knowledge base in a setting that promotes the development of an intrinsic motivation to learn." Experimentation and hands-on activities create learning experiences at a more "personal level" which promotes a unique form of memory retention and deeper learning (Mndzebele and Mckenna, 2013).

Experiential learning is a strong learning technique easily accompanied with student interest directed learning. When working with hands on activities, design flexibility and choices are easily incorporated and have been proven to be effective in student engagement. At CivE Days, students have the choice and opportunity to be as creative in their design as they like. There is a series of goals for each bridge to achieve and the students have the freedom to work towards any design goal. These choices offer opportunities for students to engage in material on a personal level. Additionally, it has been further noted by Whitman and Hardiman (2017) that when given a choice, students will choose a path closer linked to tasks that align with topics where they 
engage in learning, even if the path is more challenging. They explain this theory further by examining the goals that students set. They state that if students make goals for a project based on actual learning experiences rather than grades, then they are more willing to challenge themselves. Further, it's stated that students motivated by their own interests are more persistent, and "Difficult tasks or setbacks do not diminish their motivation or self-esteem". The CivE Days event is designed to be an event that allows students to engage in designs pertaining to their bridge project that appeal to them.

The benefits of experiential learning are further amplified when accompanied by learning through failure. There are issues that come up when a project has a strong emphasis on hands-on experience, but lacks flexibility to experience failure. Currently, the bridge design project limits learning because the design process is restricted to one attempt. By avoiding failure, students miss out on important levels of critical thinking and reflection. Learning through failure opens doors to retention through creativity, confusion, and problem solving. In a study by D'Mello and Graesser (2012), they explain the importance of learning through failure through the emotional response of the students. They state, "Cognitive processes that underlie inference generation, casual reasoning, problem diagnosis, conceptual comparisons, and coherent explanation generation are accompanied by affective states such as irritation, frustration, anger, and sometimes rage when the learner makes mistakes... On the other hand, positive affective states such as flow, delight, excitement, and eureka are experienced when tasks are completed, challenges are conquered, insights are unveiled, and major discoveries are made... Emotions are systematically affected by the knowledge and goals of the learner, as well as vice versa." They go on to explain that a balanced system is important when learning through failure. If this form of learning is uncontrolled, students will either be in states of, "(a) engagement/flow as they pursue the superordinate learning goal of mastering the material in the learning environment or (b) disengagement (boredom) when they abandon pursuit of the superordinate learning goal." CivE days is set up to encourage students to be creative without fearing failure. Allowing students to try more complex or unique designs should ideally occur in an environment where there is appropriate support when failure is experienced. This helps to prevent students from reaching the state of disengagement. The struggle to fix design problems is a positive learning opportunity. D'Mello and Graesser (2012) also explain that, "confusion is an affective state that correlates with learning gains because it accompanies impasses and the resulting deep thinking." The process that follows failure is what stimulates reflection and further experimentation. In other words, when students experience issues within their design, the reflection and problem solving to fix it will foster deeper learning and understanding.

Reflective learning is a learning technique which is very closely linked to experiential learning and learning from failure. Smart (2016) explains different reflection tactics as follows: "the individual incorporates new experiences into old understandings" and "the individual's viewpoint is challenged to such a genre that a reframing of their world is necessary". These are achieved by experiential learning and learning through failure respectively.

The reflection from experiential learning is tied to personal connections. While doing hands-on work, the reflection of past experiences enables students to confirm ideas or develop new ones (Medwell, \&Wray, 2014). Also, the process of planning requires reflection of personal knowledge and experiences. Smart and Winograd (2013) explain clearly that, "experience of 
itself does not result in learning, rather reflection is a deliberate act requiring planning, it is an active, persistent and considered process requiring the practitioner to become aware of and to challenge that which is taken for granted." Consequently, the reflection that comes with experiential learning is vital to the retention of knowledge. Knowledge that can then be personalized is better ingrained into memory.

Reflection that accompanies failure and confusion is an even stronger form of learning. The process of problem solving involves continual reflection and testing. Each success and failure as a result is then closely linked to the previous knowledge used. Paris and Winograd (2013) describe the reflective practice elements of failure as, "experimenting with the dilemma to discover the implications of various solutions, examining the intended and unintended consequences of an implemented solution and evaluating it by determining whether the consequences are desirable." As a result, a strong bond is made between new and old knowledge which solidifies the new information in long term memory. At CivE Days, students have two full days to focus and engage in the design material. Students will then have an ideal opportunity to make connections within their courses, to their life and to experiences.

\section{Implementation}

The outline for the CivE Days event was based on Carroll et al. (2018) and was broken into two days and four deliverables. The deliverables were chosen to simulate a real-world engineering project. Preliminary design of the bridges was done on the first day. Then, the actual building and testing of the bridges were done on the second day. Each deliverable had certain goals which students needed to achieve based on practical engineering design processes. This encouraged students to make connections and better understand how the material learned in their core courses could translate into solving a real engineering design problem.

The first deliverable begins with each group being given a topographic map with Points A and B on it. Students are then required to connect the two points with a road design and a bridge. In the preliminary design, students will go through the process of designing a road, doing cost analysis, cut and fill, and environmental assessment. This incorporates their transportation and materials courses. The deliverable requires students to hand in their topographic map including their proposed horizontal alignment, an elevation profile, and a cost estimate of the proposed route. Figure 1 shows students working on the topographic maps for the preliminary design. 


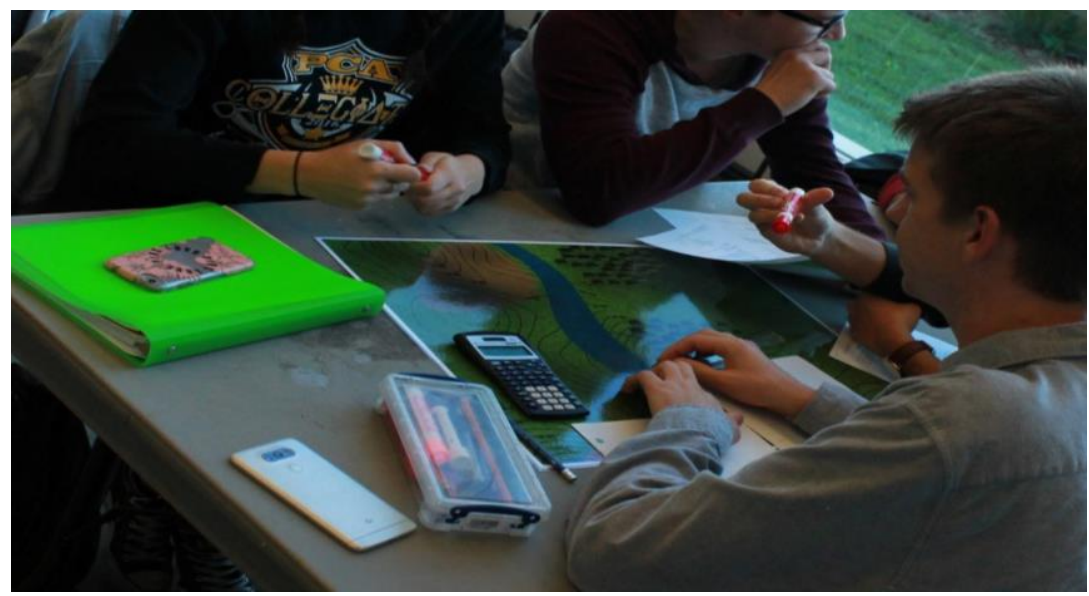

Figure 1: Students working on the first deliverable at CivE Days on their topographic map.

The second deliverable involved designing the bridge. Students analyze their design and predict the failure point, failure load, and indicate members in tension or compression. The key courses integrated in this deliverable are mechanics and statistics courses. Students calculate and submit the volume of material expected to be used, a cross sectional drawing with dimensions and properties, the required load for various forms of failure, and overall predicted failure load.

On the second day, the third and fourth deliverables involve students building and testing their bridge strength and assessing the accuracy of their statistical analysis. Initially, students are required to do a $300 \mathrm{~kg}$ test by having group members stand on their bridge. If their bridge passes this test they move on to the winch test. Figure 2 shows both forms of bridge testing.

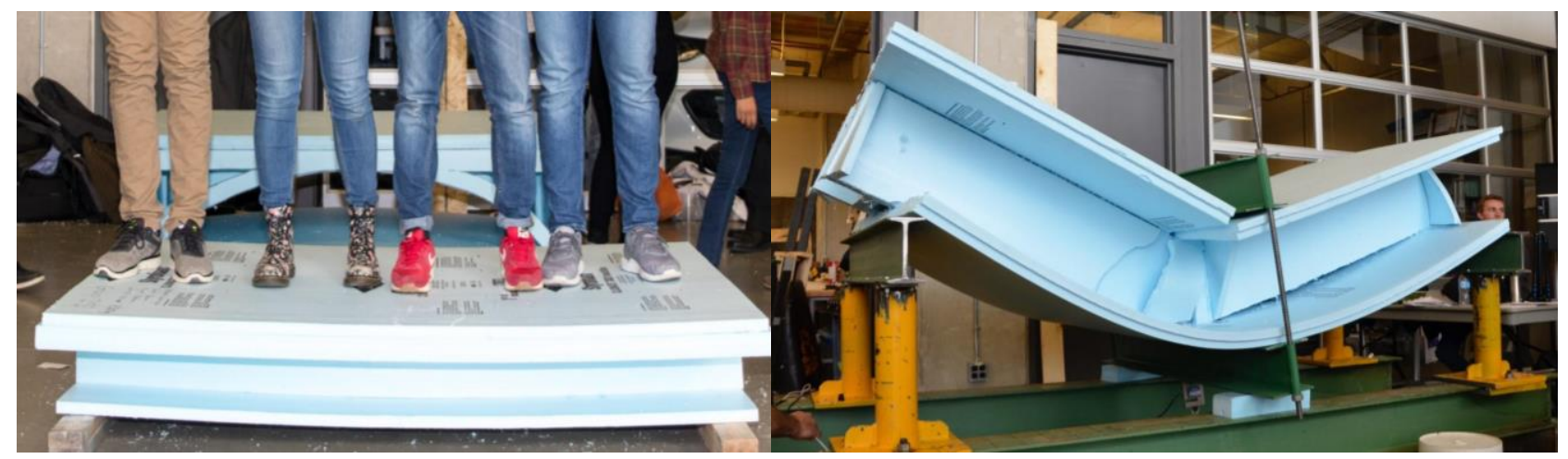

Figure 2: Bridge testing at CivE Days. Left image is the $300 \mathrm{~kg}$ test, and right image is the winch test.

At the end of the two days, two awards were given for favorite bridge designs (based on people's choice voting), and a final award was given based on the best overall design (incorporating least expensive design cost, and most accurate failure load prediction). After CivE Days, surveys were filled out by each student. The Survey was designed to measure student satisfaction, give more refined results on whether students felt they had more freedom in experimenting, and evaluate whether students felt courses were properly integrated.

To assess the effectiveness of the project, three methods were used. Firstly, the effect of CivE Days in improving the performance of the students in the popsicle sticks bridge project in the course was done by comparing results from 2017 students (who experienced CivE Days) with 
a control class, 2016 students (who did not experience CivE Days). The average class performance showed that giving students the opportunity to make an initial design and test it improves the overall success of the class. Secondly, to determine the depth of increased learning as result of CivE Days, the final bridge project design reports from 2017 and 2016 students were compared. The average marks of the reports were compared and gave indication of the overall performance of each class. Lastly, by comparing the discussion insights of each report, a more detailed understanding of student depth of learning was assessed.

\section{Results}

The data collection for CivE Days was broken into three methods. These methods were, student survey responses, bridge project grades, and reflection report feedback. These various methods aimed to gauge student satisfaction and to quantify the effectiveness of the event in helping with the popsicle stick bridge design project. Overall, participation in the optional CivE Days event was successful, with 121 out of 165 students choosing to partake.

As described earlier, after CivE Days, students were given an optional survey to complete, and $83 \%$ of participating students filled out the survey. The survey aimed to assess the student satisfaction and to determine the immediate student response for the course integration and freedom for creativity. The results showed that $83 \%$ of people who participated chose to come because of the content being covered. Fifty-seven percent of those students thought it seemed interesting and fun, while $26 \%$ wanted the opportunity to prepare for the bridge project. The remaining $17 \%$ were interested in free food and prizes. Figure 3 below shows the general student responses to the survey.

\section{Survey Results}

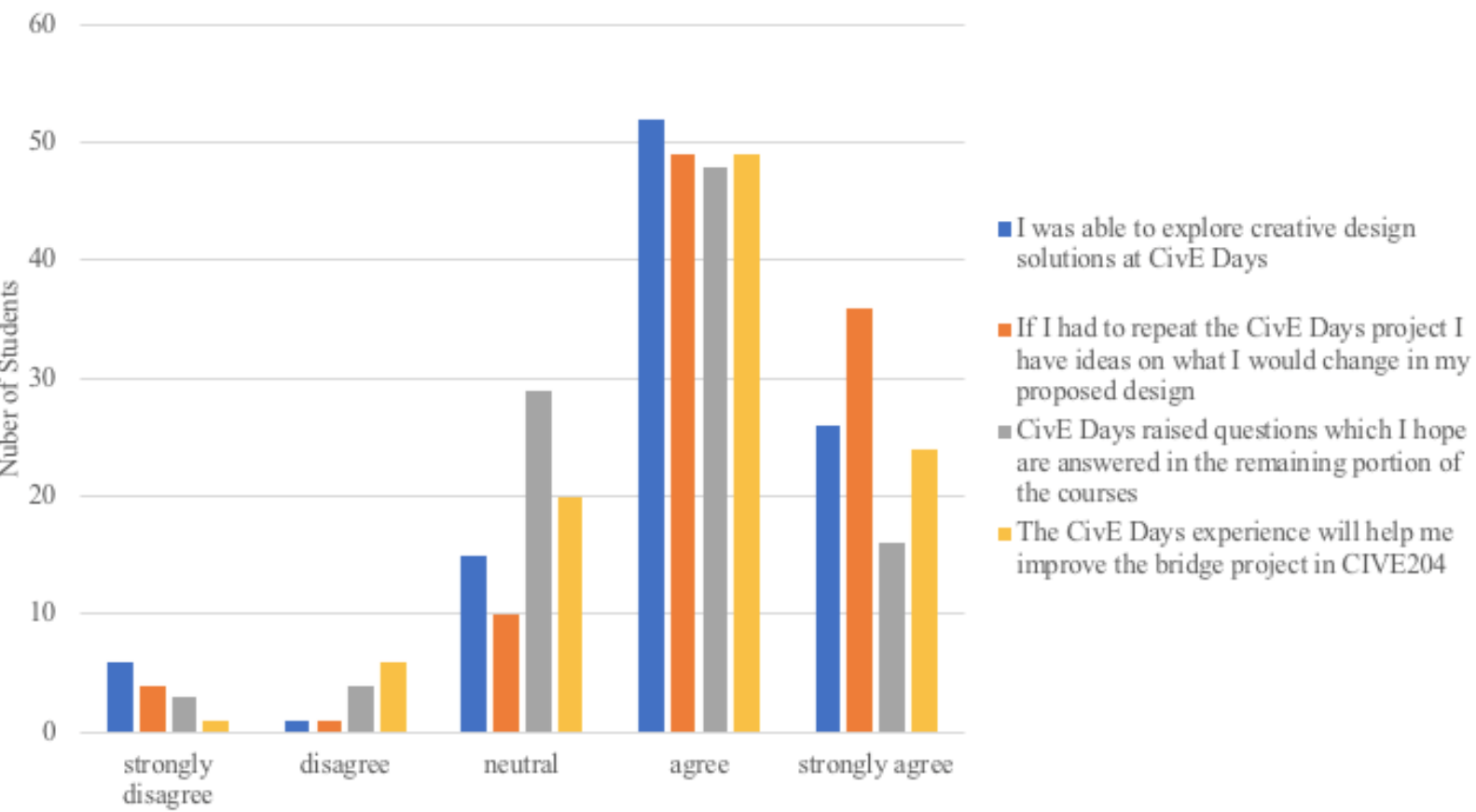

Figure 3: CivE Days survey question responses. Number of students with their level of agreement to the statements shown in the legend. 
When asked if students wanted to participate in a similar event again in the future, $86 \%$ said they would. It is also shown in Figure 4 that most of the students preferred not having a graded component to the event.

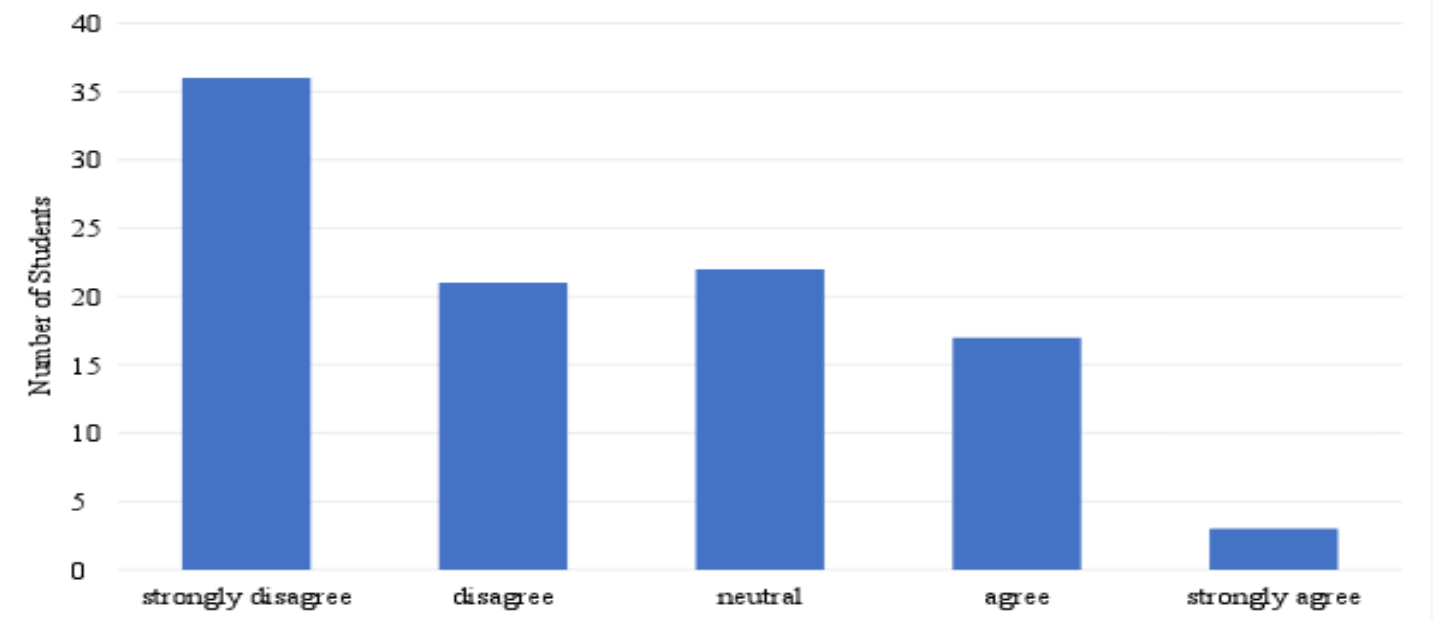

Figure 4: Level of student agreement to the statement "I would like there to be a graded component to CivE Days".

For measuring the effectiveness of the course, Figures 5 and 6 show the student responses. 

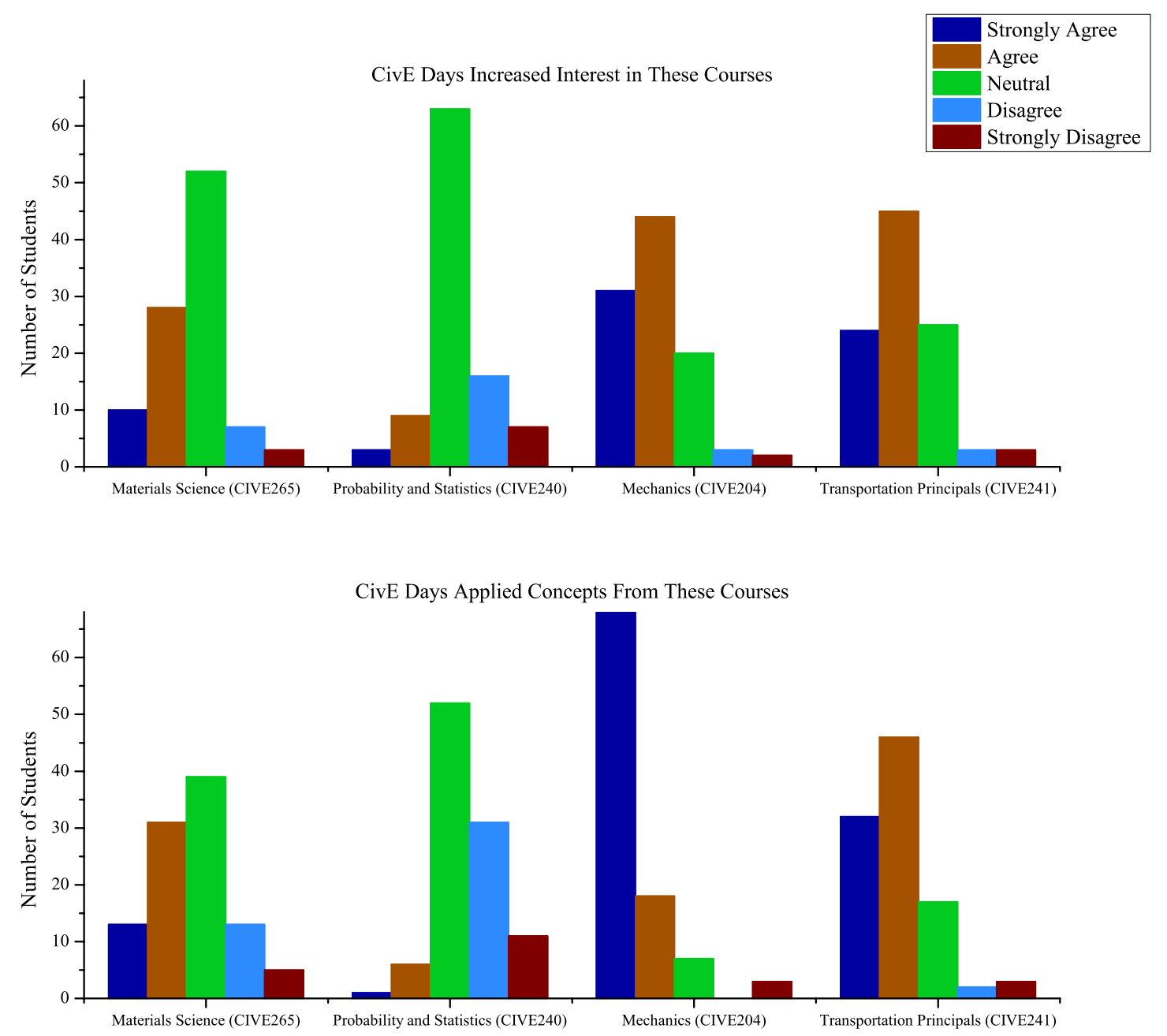

Figure 5: Students survey responses to being asked if CivE Days "Increased Interest" (top) or "Applied Concepts" (bottom) of each of their four courses being taken. Students indicated their level of agreement to both statements for each of the courses.

The results from the 2017 class grades compared to the 2016 class are shown in Figure 6 . The overall bridge testing performance had a $4 \%$ grade increase with $2 \%$ more of the class being able to withstand the minimum strength to weight squared ratio of 250 . The 2016 class had 89 out of 121 students achieve the goal and 124 out of 165 students in the 2017 class. Also, the average of the final report and the overall project mark of the 2017 class increased by $7 \%$ compared to the 2016 class. 

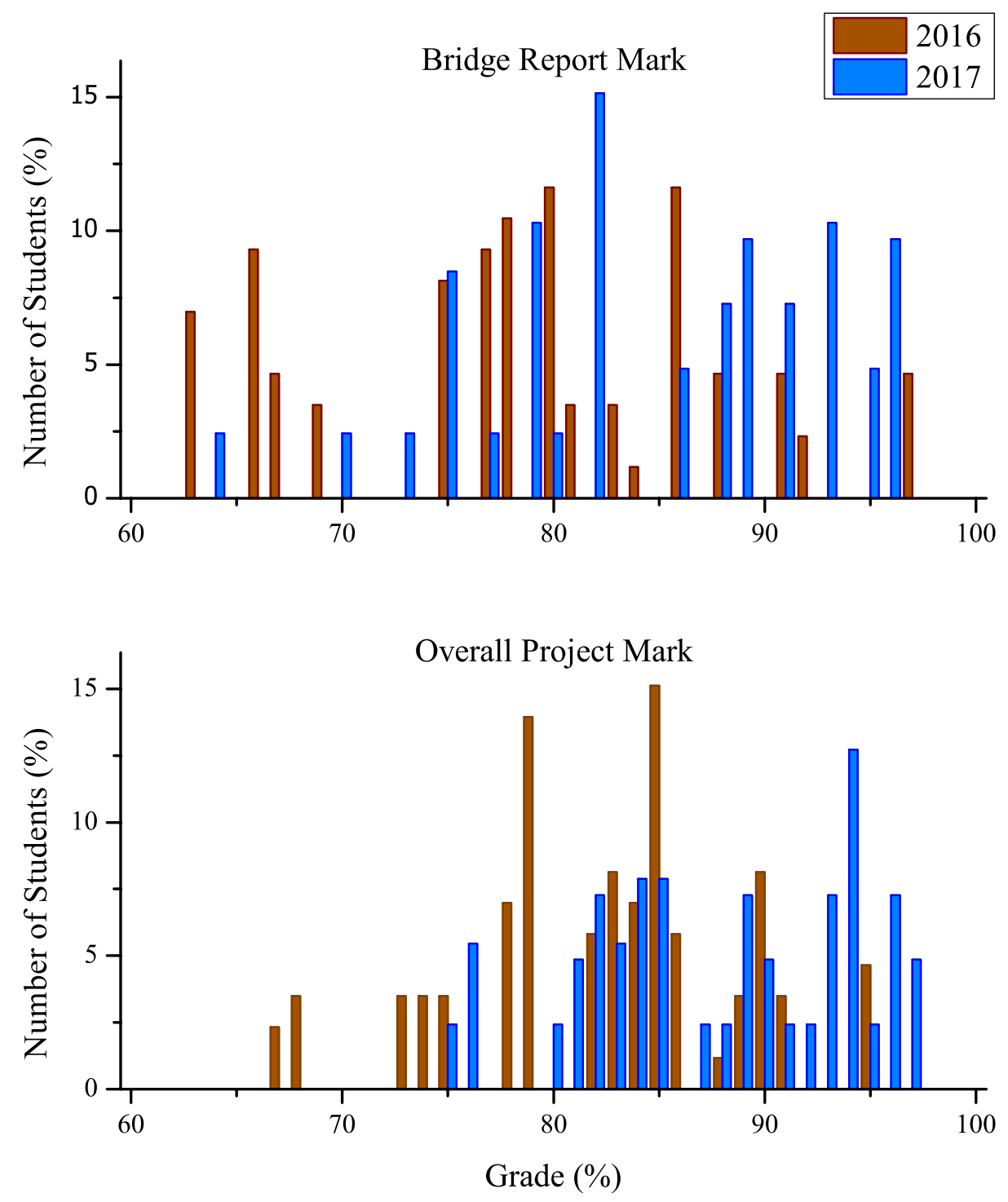

Figure 6: Overall bridge project grade distribution for both the 2016 and 2017 classes. Top figure shows the final bridge report mark grading distribution. Bottom figure shows the overall project grade including bridge performance, report and preliminary design.

The final form of data collected was student responses through the reflection report in the course project. The reflection reports discussed the direct impact of CivE Days on the popsicle sticks bridge design project. Common themes included CivE Days being a fun and rewarding experience that connected them to applications of their courses. Students were happy with how fun it was and felt that it was a nice break from the stress of school. However, some students thought that the benefits of CivE Days to their bridge design project were limited. They felt that the bridge building materials used for both projects were too different. Many of the problems faced were material specific and therefore limited the usefulness of the CivE Days as a practice design. 


\section{Discussion}

The results can be broken into three categories based on the goals of CivE Days. These categories are student satisfaction and creativity, course integration, and being a help for the popsicle sticks bridge project.

\section{Student Satisfaction and Creativity}

The overall student feedback was positive. Most of the students $(86 \%)$ indicated that they would like to participate in an event like this again. One student in a reflection report said, "It makes learning the theory behind everything seem worth it when you see what you can do with it". Students also acknowledged that CivE Days enabled them to be more creative in their designs. Figure 3 illustrated that the majority of students are in agreement to the statement, "I was able to explore creative design solutions at CivE Days". Additionally, the students were satisfied with the event being ungraded, as seen in Figure 4. Students were happy with the prizes and the food provided, which was mentioned in their reflection reports. The most common comment for improvement was to choose different building materials and to shorten the event length.

\section{Course Integration}

The integration of the courses resulted in it being a more difficult task. Students agreed that CivE Days successfully incorporated their mechanics and transportation courses through building the bridge and roadway. However, there was a noted lack of content from their other courses. This can be seen in Figure 5. Many students remained neutral when asked if they experienced increased interest in their material sciences and statistics courses. The response was the same when asked if they thought the courses were applied. This is further emphasized with a quote from a reflection report stating, "The design days had a very positive impact on my understanding of the concepts taught in [the mechanics course], but had a negative impact on the other courses. They decreased our class time in statistics, materials, and calculus, while not providing any additional instruction or learning experience in those two classes". This shows that the course integration was only partially successful. To improve on this, deliverables should be modified to better incorporate other courses. Some students suggested holding the event earlier in the term so it could help in the preliminary phases of the bridge design project.

\section{Bridge Project}

CivE Days serving as a tool to help in the bridge design project had mixed responses. In the survey completed immediately after the event in Figure 3, students indicate that the CivE Days experience will help with their bridge project. Many students agree, as stated in a report, "The design days helped to brainstorm ideas for our popsicle stick [bridge project] and think about ways in which the bridge may fail". Many students gave specific examples of problems they identified and fixed for the bridge project.

While many students saw the connection between design days and the bridge project, some students question the effectiveness of the event. A common concern was the difference of material being used as CivE Days used Styrofoam while the course project used popsicle sticks. One student stated that, "the hardest part of making and designing the bridge from the project was figuring out a way to effectively use the popsicle sticks to create a strong bridge." Since the material used for building at CivE Days was Styrofoam, it was hard for students to correlate the CivE Days design experience to the bridge project. Students also mentioned that there was less 
material design constraints at CivE Days which made it easier than the bridge project. This ended up not giving students the needed prior experience to designing under strict constraints. One student suggested to provide a variety of building material for CivE Days and then students can experiment with what interests them.

Although students shared these concerns, many were still happy with their experience and one stated that, "Even though the design days did not directly benefit the project, it helped me gain some practical experience on how focused and accurate one must be when building since that's what it came down to".

When considering the grade distribution of the 2017 class, which participated in CivE Days, to the 2016 class that did not participate in CivE Days there was an improvement for the students who participated in CivE Days. The class average for the overall grade of the bridge design project improved 7\% from 2016 to 2017. Also, when looking at Figure 6 the distribution of grades had a positive shift. These, along with the increased bridge testing results, indicate that there was a benefit to CivE Days. Bridge designs were not only stronger, the reflections and observations in the final reports improved.

\section{Conclusion}

The main goals of the CivE Days event were to allow students to better understand the bridge design project and how the information from the different courses is integrated. It was reported that many students found CivE Days to be fun and beneficial to the learning, but some areas need improvement. The preparation for the bridge project had mixed responses from students, who had concerns with the materials being used. Despite this, there was a noticeable increase in student grades from the 2017 class that participated in CivE Days and the 2016 class that did not. The course integration was acknowledged to be effective for the mechanics and transportation courses, but not for the material sciences and statistics courses. Improvements to be made include using alternative building materials and modifying the deliverables to better incorporate all courses.

CivE Days also aimed for students to experience student interest directed learning, experiential learning, learning through failure and reflective learning. The event successfully in this regard. Many students agreed in the survey that they felt free to be creative in their designs. There were also many students who discussed in their reports the errors that they found and modified in their designs. Additionally, the quality of the bridge project reports written by the students increased substantially from the prior year, exemplifying the improved reflections in their design.

Overall, CivE Days was successful in achieving its goals, with noted improvements to be made for future years. The majority of the students enjoyed the event and indicated that they would like to participate in a similar event again in the future. Students were satisfied and the results indicate that students learning improved as a result of CivE Days. 


\section{Acknowledgement}

The authors would like to acknowledge the Center for Teaching Excellence (CTE) at University of Waterloo (UW), the department of Civil and Environmental Engineering at UW, and the IDEAS Clinic at UW for funding this project.

\section{Bibliography}

Balkos, K., Dow, B., Shams, S., Al-Hammoud, R., Emelko, M. B., Walbridge, S. \& Bachmann, C. " Pedagogical Skill Development Through the Horizontal Integration of a SecondYear Engineering Curriculum," in Proc. ASEE 124th Annual Conference and Exposition (Columbus, OH; June 2017), 14 pp., 2017.

Carroll, J. C., Sipes, S., Benton, J. W., Aucoin, T., de Zamacona Cervantes, G. E., O'neil, A., and Syed, S. M. (2017). Lessons Learned in K-12 Engineering Outreach and Their Impact on Program Planning. 2017 ASEE Annual Conference, Columbus, OH.

https://peer.asee.org/lessons-learned-in-k-12-engineering-outreach-and-their-impact-onprogram-planning-evaluation

Current, K., \& Kowalske, M. (2016). The effect of instructional method on teaching assistants' classroom discourse. Chem. Educ. Res. Pract., 17(3), 590-603.

D’Mello, S., \& Graesser, A. (2012). Dynamics of affective states during complex learning. Learning And Instruction, 22(2), 145-157.

Lynch, R., McNamara, P., \& Seery, N. (2012). Promoting deep learning in a teacher education programme through self- and peer-assessment and feedback. European Journal of Teacher Education, 35(2), 179-197.

Medwell, J., \& Wray, D. (2014). Pre-service teachers undertaking classroom research: developing reflection and enquiry skills. Journal Of Education For Teaching, 40(1), 6577.

Mndzebele, S., \& Mckenna, S. (2013). Applying a student curriculum discourse in higher education teaching and learning. Africa Education Review, 10(1), 1-17.

Paris, S., \& Winograd, P. (2003). The role of self-regulated learning in contextual teaching: principals and practices for teacher preparation. Office Of Educational Research And Improvement.

Smart, F. (2016). Poetic transcription with a twist: An approach to reflective practice through connection, collaboration and community. Innovations In Education And Teaching International, 54(2), 152-161.

Whitman, G., \& Hardiman, M. (2017). Assessment and the learning brain. Retrieved from http://HttpsL//www.nais.org/magazine/independent-school/winter-2014/assessment-andthe-learning-brain/ 